\title{
Differential Role of Rapamycin and Torin/KU63794 in Inflammatory Response of 264.7 RAW Macrophages Stimulated by CA-MRSA
}

\author{
Rebekah K. H. Shappley ${ }^{1}$ and Thomas Spentzas ${ }^{1,2}$ \\ ${ }^{1}$ Division of Pediatric Critical Care Medicine, University of Tennessee Health Science Center, Memphis, TN 38139, USA \\ ${ }^{2}$ Children's Foundation Research Institute at Le Bonheur Children's Hospital, 50 North Dunlap, Memphis, TN 38103, USA \\ Correspondence should be addressed to Thomas Spentzas; tom.spentzas@gmail.com
}

Received 4 January 2014; Accepted 3 March 2014; Published 1 April 2014

Academic Editor: G. Rogler

Copyright (C) 2014 R. K. H. Shappley and T. Spentzas. This is an open access article distributed under the Creative Commons Attribution License, which permits unrestricted use, distribution, and reproduction in any medium, provided the original work is properly cited.

\begin{abstract}
Background. Rapamycin suppresses the RAW264.7 macrophage mediated inflammatory response but in lower doses induces it. In the present study, we tested the suppression of the inflammatory response in the presence of mTOR 1 and 2 inhibitors, Torin and KU63794. Methods. RAW264.7 cells were stimulated for $18 \mathrm{hrs}$ with $10^{6}$ to $10^{7} \mathrm{CFU} / \mathrm{mL}$ inocula of community-acquired- (CA-) MRSA isolate, USA400 strain MW2, in the presence of Vancomycin. Then, in sequential experiments, we added Torin, KU63794, and Rapamycin alone and in various combinations. Supernatants were collected and assayed for TNF, IL-1, IL-6, INF, and NO. Results. Rapamycin induces $10-20 \%$ of the inflammatory cascade at dose of $0.1 \mathrm{ng} / \mathrm{mL}$ and suppresses it by $60 \%$ at dose of $10 \mathrm{ng} / \mathrm{mL}$. The induction is abolished in the presence of Torin KU63794. Torin and KU63794 are consistently suppressing cytokine production 50-60\%. Conclusions. There is a differential response between Rapamycin (mTOR-1 inhibitor) and Torin KU63794 (mTOR 1 and 2 inhibitors). Torin and KU63794 exhibit a dose related suppression. Rapamycin exhibits a significant induction-suppression biphasic response. Knowledge of such response may allow manipulation of the septic inflammatory cascade for clinical advantages.
\end{abstract}

\section{Introduction}

Sequential cytokine release from macrophages propels the inflammatory response in infection. An overwhelming cytokine release turns simple infection into sepsis $[1,2]$. The host appears to mount a biphasic cytokine release response: first mounting a proinflammatory and then an anti-inflammatory response which quells the positive feedback loop of the cytokine storm [3]. The anti-inflammatory response or "immunoparalysis" refers to the diminished ability of the body to mount an appropriate cytokine storm and immune response and can lead to secondary infections $[4,5]$.

Our previous research has focused on the signaling pathways of the murine macrophage in response to CAMRSA. We have shown that the agonism of the NMDA receptor increases and antagonism of the same receptor diminishes the TNF response [6]. Downstream from the
NMDA, the phosphoinositide-3 kinase/akt (PI3/AKT) also influences such response $[6,7]$. The next downstream signaling molecule is the mammalian target of Rapamycin (mTOR complex). The role of mTOR as a central controller of cell growth, proliferation, and metabolism has been described but many aspects are unclear $[8,9]$. Previous studies by our group have shown that inhibition of mTOR by Rapamycin has a dose-dependent biphasic response on TNF secretion [7]. At very low doses, Rapamycin increases TNF production, but, at tenfold higher doses, TNF secretion is diminished. Rapamycin works by binding cytosolic FK-binding protein 12 (FKBP12) and together these form a complex that binds the mTOR complex 1 (mTORC1) [10-15]. mTORC1 is a serine/threonine phosphokinase which functions as a redox sensor, regulates cell growth and proliferation [16]. Rapamycin may act also on mTOR2 but it is not clear how this pathway influences the inflammatory cascade [17]. CD-34 derived dendritic cells undergo apoptosis when 
exposed to Rapamycin, but monocytes and macrophages do not [18].

It is known that these have various anabolic and catabolic activities; however, the relative role of mTORC1 and mTORC2 in macrophage cytokine stimulation is unknown.

There exist two mTORC1 and 2 inhibitors: KU63794 and Torin; although their role is not clear, it appears to exhibit more complete mTORC inhibition than Rapamycin $[19,20]$. This study explores their role in inflammatory cascade in comparison to Rapamycin action. Investigation of the inflammatory pathway is important, since Rapamycin and Torin are currently in use in posttransplant and cancer patients. Additionally, knowledge of the pathway may also offer advantages in the immunomodulation of sepsis. In this paper, we hypothesize that the mTORC 1 and 2 inhibitors will have different effects on cytokine stimulation than Rapamycin in a murine macrophage model stimulated by CA-MRSA.

\section{Methods}

Bacteria. The bacteria selected for this study were the CAMRSA strain MW-2, a Midwestern strain known to cause serious invasive disease. The MW-2 strain is representative of the USA-400 isolates, one of the major CA-MRSA pathogens in the United States [21]. Bacteria were grown at $37^{\circ} \mathrm{C}$ to the late logarithmic phase in tryptic soy broth (Becton, Dickinson and Company, Sparks, MD, USA), then washed in endotoxin-free phosphate-buffered saline. Colony counts were used to determine concentration of bacteria. Based on our previously published data with CA-MRSA we aimed for a concentration of bacteria of $10^{6}-10^{7} \mathrm{cfu} / \mathrm{mL}[6,7,22]$. The minimum inhibitory concentration was determined using the E-test method in the microbiology laboratory at Le Bonheur Children's Hospital $(\mathrm{LBCH})$ and was susceptible to Vancomycin with MIC of $<0.5 \mu \mathrm{g} / \mathrm{mL}$.

Cell Culture. The cell culture consisted of RAW264.7 murine macrophage-like cells purchased from ATCC. The cells were cultured in Dulbecco's modified Eagle's medium (Mediatech, Herdon, VA, USA) and supplemented with $10 \%$ fetal bovine serum (HyClone, Logan, UT, USA) and $2 \mathrm{mM}$ glutamine (GIBCO, Grand Island, NY, USA). For experiments, $1 \times 10^{6}$ cells were placed in each well of 24-well tissue culture plates (Becton Dickinson, Franklin Lakes, NJ, USA).

Vancomycin was purchased through the Department of Pharmacy at LBCH from Hospira (Lake Forest, IL, USA) and is used to moderate the uncontrolled growth of MRSA and massive TNF production. A clinically achievable concentration of Vancomycin, $20 \mu \mathrm{g} / \mathrm{mL}$ was added to the cell cultures prior to the addition of live staphylococci.

This was completed in parallel with various strengths of Torin (Tocris Bioscience, Bristol, UK) and KU63794 (Tocris Bioscience, Bristol, UK) to create a dose curve. These supernatants were harvested and analyzed (method below) and optimal dosing of Torin and KU63794 was identified. The tested concentrations of Vancomycin, Rapamycin, Torin, and KU63794 had no effect on the viability of the RAW264.7 cells as determined by visual inspection of the monolayer under a low power microscopic view.

Once optimal dosing of Torin and KU63794 were known, the experiment was repeated with combinations of Torin, Rapamycin $(0.1,1,10$, and $100 \mathrm{ng} / \mathrm{mL})[18,23]$, and KU63794. Control levels TNF, IL-1, IL-6, INF and NO (Rapamycin served as the control) were contrasted with stimulation in the presence of various combinations of mTORC1 inhibitor Rapamycin, and mTORC 1\&2 inhibitor Torin, and mTORC 1\&2 inhibitor KU63794.

After incubation, cell-free supernatants were collected and assayed for cytokine concentrations using solid phase sandwich enzyme-linked immunoabsorbent assay for TNF$\alpha$ (eBioscience, San Diego, CA, USA), IFN (PBL Biomedical, Piscataway, NJ, USA), IL-1 (R\&D Systems, Minneapolis, MN, USA), and IL-6 (eBioscience, San Diego, CA, USA). NO concentrations were examined using the Griess reaction (Promega, Madison, WI, USA). TNF secretion measurements were validated with an average of three well replicates performed three times, totaling nine samples. There exists intrinsic experimental variation within TNF, IL-1, IL-6, INF, and NO production in different cell culture flasks due to unique cell culture and endogenous macrophage differences, which is consistent with our previous studies $[6,7,22$, 24]. Cells from the same population were used to minimize variation for all experiments and the responses were ranked.

mTOR Activation. The activation of mTOR was estimated by MSD phosphoprotein assay whole cell lysate kit. The fraction phospho(Ser2448)/total mTOR was computed at the $5 \mu \mathrm{g}$ cell lysate at 3 duplicates. The cells were exposed to MRSA without addition of mTOR inhibitors, and subsequently with the addition of Rapamycin $0.1,1,10$, and $100 \mathrm{ng} / \mathrm{mL}$, Torin 1 and $5 \mathrm{ng} / \mathrm{mL}$, and KU63794 1 and $5 \mathrm{ng} / \mathrm{mL}$.

Cells Viability. KU63794, Torin, and Rapamycin at doses used in our experiments had no effect on the viability of the RAW264.7 cells as determined by a low-power microscopic inspection of the monolayer and exclusion of $0.2 \%$ trypan blue dye. Cell viability was confirmed using 3-(4,5-dimethylthiazol-2-yl)-5-(3carboxymethoxyphenyl)-2-(4-sulfophenyl)-2H-tetrazolium, inner salt (MTS) according to the manufacturer's instructions (Promega, Madison, WI, USA) [25]. The MTS reagent is reduced by metabolically active cells into a colored formazan product whose absorbance is then measured. In brief, MTS solution was added to wells of a 96-well microtiter plate, and the cells were incubated for $2 \mathrm{~h}$. The absorbance at $490 \mathrm{~nm}$ was then measured.

Data Analysis. The data were analyzed with R 2.12 .2 software. All the results are ranked and expressed as percent fold increase over the control. The percentile can easily be transformed to the actual value because the actual control value $(\mathrm{pg} / \mathrm{mL})$ for each experiment is given. For example, when the TNF response is $80 \%$ of the control and the actual control value is $33,561 \mathrm{pg} / \mathrm{mL}$, then the response is $0.8 \times 33,561 \mathrm{pg} / \mathrm{mL}=26,849 \mathrm{pg} / \mathrm{mL}$. The concentration of NO 
TABLE 1: The table indicates the reduction from the control of RAW264.7 macrophages inflammatory response in the presence of $0,2.5,5$, and $10 \mathrm{ng} / \mathrm{mL}$ Torin (up) and KU63794 (down).

\begin{tabular}{|c|c|c|c|c|c|}
\hline & $\begin{array}{c}\mathrm{TNF} \\
(\%-\mathrm{pg} / \mathrm{mL})\end{array}$ & $\begin{array}{c}\text { IL-1 } \\
(\%-p g / m L)\end{array}$ & $\begin{array}{c}\text { IL-6 } \\
(\%-p g / m L)\end{array}$ & $\begin{array}{c}\text { INF } \\
(\%-p g / m L)\end{array}$ & $\begin{array}{c}\mathrm{NO} \\
(\%-\mu \mathrm{M})\end{array}$ \\
\hline \multicolumn{6}{|c|}{ Torin $(\mathrm{ng} / \mathrm{mL})$} \\
\hline 0 & $\begin{array}{c}100 \% \\
33,561 \pm 4,027\end{array}$ & $\begin{array}{c}100 \% \\
555 \pm 83\end{array}$ & $\begin{array}{c}100 \% \\
845 \pm 127\end{array}$ & $\begin{array}{c}100 \% \\
96 \pm 14\end{array}$ & $\begin{array}{c}100 \% \\
25.3 \pm 3.8\end{array}$ \\
\hline 2.5 & $68 \%{ }^{*}$ & $44 \%^{*}$ & $54 \%^{*}$ & $37 \%{ }^{*}$ & $51 \%^{*}$ \\
\hline 5 & $48 \% *$ & $43 \% *$ & $49 \% *$ & $40 \%{ }^{*}$ & $48 \%{ }^{*}$ \\
\hline 10 & $46 \%{ }^{*}$ & $44 \%^{*}$ & $48 \%{ }^{*}$ & $41 \%^{*}$ & $46 \%{ }^{*}$ \\
\hline \multicolumn{6}{|c|}{ KU63794 (ng/mL) } \\
\hline 0 & $\begin{array}{c}100 \% \\
32,865 \pm 3,615\end{array}$ & $\begin{array}{c}100 \% \\
432 \pm 52\end{array}$ & $\begin{array}{c}100 \% \\
743 \pm 89\end{array}$ & $\begin{array}{c}100 \% \\
95 \pm 11\end{array}$ & $\begin{array}{c}100 \% \\
23.2 \pm 2.8\end{array}$ \\
\hline 2.5 & $69 \%^{*}$ & $47 \%^{*}$ & $55 \%^{*}$ & $48 \%{ }^{*}$ & $42 \% *$ \\
\hline 5 & $53 \%^{*}$ & $47 \%{ }^{*}$ & $52 \%^{*}$ & $33 \%^{*}$ & $48 \%^{*}$ \\
\hline 10 & $49 \%{ }^{*}$ & $44 \%{ }^{*}$ & $48 \%{ }^{*}$ & $41 \%^{*}$ & $51 \%{ }^{*}$ \\
\hline
\end{tabular}

The first line indicates the response without Torin or KU63794 $(0 \mathrm{ng} / \mathrm{mL})$ which is used as control (100\% response) and the subsequent values are expressed as $\%$ of such responses.

* Indicates statistical significance $(P<0.05)$ from the control.

TNF: tumor necrosis factor, IL-1: interleukin 1, IL-6: interleukin 6, INF: interferon, and NO: nitric oxide.

is measured in $\mu \mathrm{M}$. The data were graphed as boxplot mean and $1.96 \mathrm{SE}$.

The activation of mTOR computed as a fraction of the phospho- versus total mTOR and was graphed as boxplot.

\section{Results}

3.1. Torin and KU63794. First, the effects of $0,2.5,5$, and $10 \mathrm{pg} / \mathrm{mL}$ doses of Torin and KU63794 were tested. Without Torin, the MW2 CA-MRSA stimulated RAW264.7 macrophages produced $33,561 \mathrm{pg} / \mathrm{mL}$ TNF and this production was used as control, that is, $100 \%$ response. The addition of $2.5 \mathrm{ng} / \mathrm{mL}$ reduced the response to $22,821 \mathrm{pg} / \mathrm{mL}$ or $68 \%$ $(P<0.05)$. Further increase of added Torin at 5 and $10 \mathrm{ng} / \mathrm{mL}$ reduced the TNF to $16,109 \mathrm{pg} / \mathrm{mL}(48 \%)$ and $15,438 \mathrm{pg} / \mathrm{mL}$ (46\%). Those reductions were different from the control $(P<$ $0.05)$ and the $2.5 \mathrm{pg} / \mathrm{mL}$ of Torin but not statistically different from each other. The effects on other cytokines also show reduction from the control. IL-1 was produced at $555 \mathrm{pg} / \mathrm{mL}$ without Torin (control 100\%) and was reduced to $244 \mathrm{pg} / \mathrm{mL}$ (44\%), $239 \mathrm{pg} / \mathrm{mL}(43 \%)$, and $245 \mathrm{pg} / \mathrm{mL}(44 \%)$ at doses of $2.5,5$, and $10 \mathrm{pg} / \mathrm{mL}$, respectively. Although all were different than the control $(P<0.05)$, they were not statistically different from each other. Therefore, the dose effect reduction of 2.5 versus 5 or $10 \mathrm{ng} / \mathrm{mL}$ of Torin observed with TNF was not seen with IL-1. IL-6, INF, and NO produced similar pattern reduction as seen with IL-1. The Torin effects on TNF, IL-1, IL-6, INF, and NO are presented in Table 1 (upper part) and depicted as graphs in Figure 1(a).

The responses with KU63794 were similar. Without KU63794, the MW2 CA-MRSA stimulated RAW264.7 macrophages produced and average of $32,865 \mathrm{pg} / \mathrm{mL}$ TNF (slightly different than the average $33,561 \mathrm{pg} / \mathrm{mL}$ observed in the Torin series), and this average was used as a control, that is, a 100\% response. Addition of KU63794 at 2.5, 5, and
$10 \mathrm{ng} / \mathrm{mL}$ reduced the production to $22,677 \mathrm{pg} / \mathrm{mL}(69 \%)$, $17,417 \mathrm{pg} / \mathrm{mL}$ (53\%), and $16.104 \mathrm{pg} / \mathrm{mL}$ (49\%). All these values are different than the control $(P<0.05)$ and the response at $2.5 \mathrm{ng} / \mathrm{mL}$ is different than the response at $5 \mathrm{ng} / \mathrm{mL}$ or $10 \mathrm{ng} / \mathrm{mL}(P<0.05)$. IL-1 was produced at $432 \mathrm{pg} / \mathrm{mL}$ without Torin (control 100\%) and was reduced to $202 \mathrm{pg} / \mathrm{mL}$ (47\%), $203 \mathrm{pg} / \mathrm{mL}(47 \%)$, and $190 \mathrm{pg} / \mathrm{mL}(44 \%)$ at $2.5 \mathrm{pg} / \mathrm{mL}$, $5 \mathrm{pg} / \mathrm{mL}$, and $10 \mathrm{pg} / \mathrm{mL}$, respectively. All KU63794 additions are different than the control $(P<0.05)$ but not from each other; that is, the dose effect is not present. The KU63794 effects on TNF, IL-1, IL-6, INF, and NO are presented in Table 1 (lower part) and depicted as graphs in Figure 1(b). Our dose curves experiments indicated that Torin and KU63794 have diminished suppression ( $~ 80-99 \%$ of the control) at doses of $2,1.5$, and $1 \mathrm{ng} / \mathrm{mL}$ and plateau to not statistically significant different values at doses $0.9,0.7,0.5,0.3,0.1$, and $0.01 \mathrm{ng} / \mathrm{mL}$.

The viability of the cells was tested as described in Section 2. There were no changes in the spectrum of tested doses.

3.2. Rapamycin and Torin. The effects of 0, 0.1, 10, and $100 \mathrm{ng} / \mathrm{mL}$ Rapamycin were compared to the same Rapamycin dosing and Torin $5 \mathrm{ng} / \mathrm{mL}$. The stimulated macrophages produced an average of $32,758 \mathrm{pg} / \mathrm{mL}$ of TNF without Rapamycin and this was used as control (100\%). When Rapamycin was added at doses of $0.1,10$, or $100 \mathrm{ng} / \mathrm{mL}$, the average production of TNF was $37,672 \mathrm{pg} / \mathrm{mL}(115 \%)$, $21,620 \mathrm{pg} / \mathrm{mL}(66 \%)$, and $20,965 \mathrm{pg} / \mathrm{mL}(64 \%)$, respectively. All the responses are different than the control $(P<0.05)$. However, the $0.1 \mathrm{ng} / \mathrm{mL}$ dose response is different than the $10 \mathrm{ng} / \mathrm{mL}$ and $100 \mathrm{ng} / \mathrm{mL}$ and increases rather than suppresses the TNF response. The IL-1 response without Rapamycin was $486 \mathrm{pg} / \mathrm{mL}$ (establishing the $100 \%$ control) and similar was the response with the addition of Rapamycin 

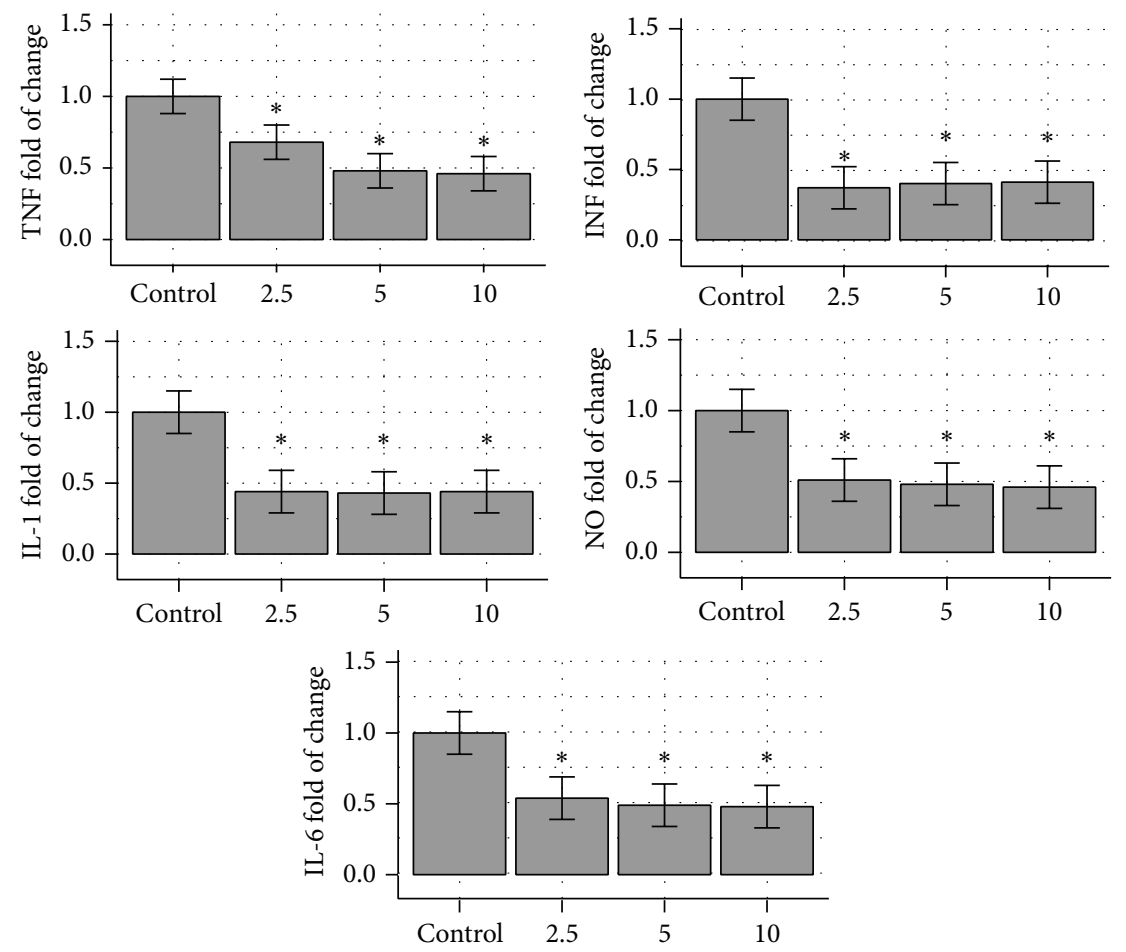

(a)
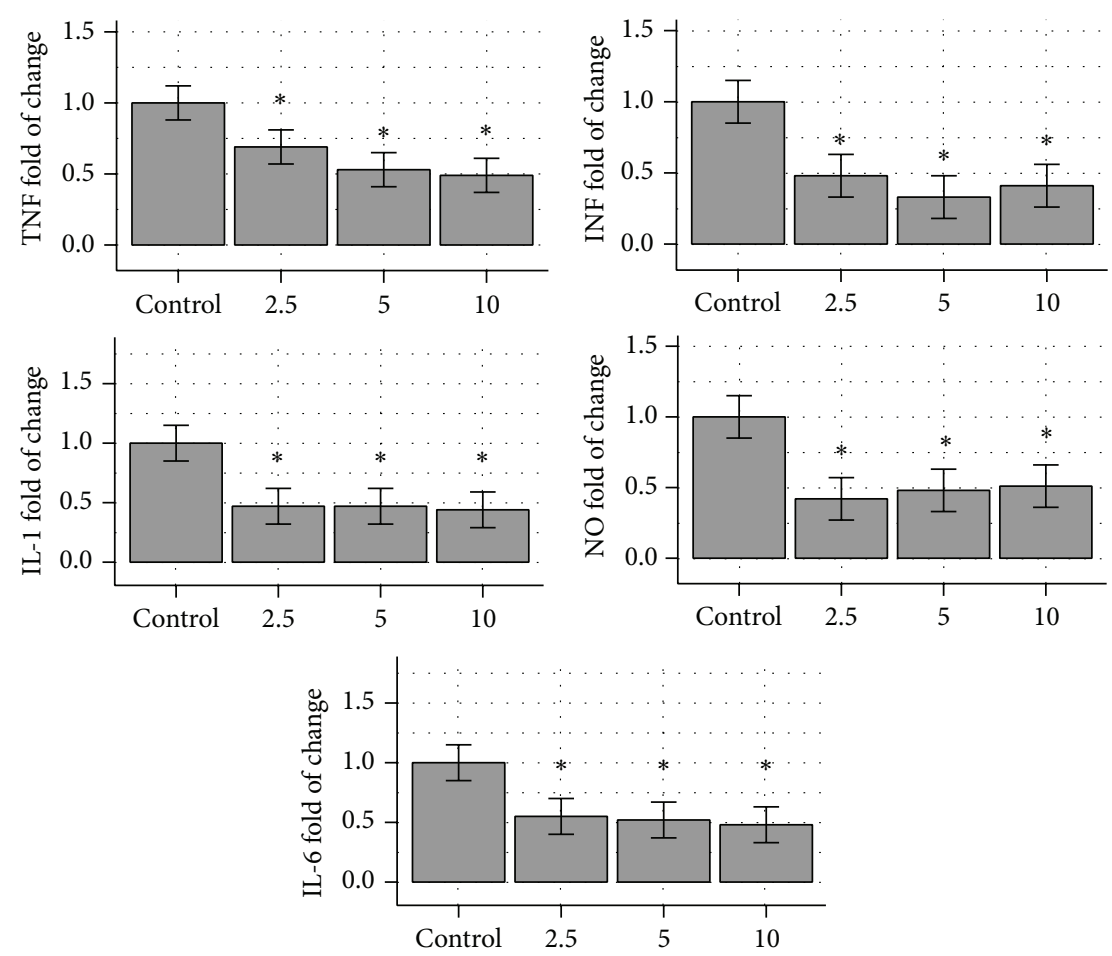

(b)

FIgURE 1: (a) A graphic representation of Table 1. The la indicates the reduction from the control of RAW264.7 macrophages inflammatory response of TNF, IL-1, IL-6, INF, and NO, respectively, in the presence of $0,2.5,5$, and $10 \mathrm{ng} / \mathrm{mL}$ Torin. The graphs are depicted as a percent of the control response, that is, without Torin $(0 \mathrm{ng} / \mathrm{mL})$. TNF: tumor necrosis factor, IL-1: interleukin 1, IL-6: interleukin 6, INF: interferon, and NO: nitric oxide. (b) It is a graphic representation of Table 1. The $1 \mathrm{~b}$ indicates the reduction from the control of RAW264.7 macrophages inflammatory response of TNF, IL-1, IL-6, INF, and NO, respectively, in the presence of 0, 2.5, 5, and $10 \mathrm{ng} / \mathrm{mL} \mathrm{KU} 63794$. The graphs are depicted as a percent of the control response, that is, without KU63794 (0 ng/mL). TNF: tumor necrosis factor, IL-1: interleukin 1, IL-6: interleukin 6, INF: interferon, and NO: nitric oxide. 
TABLE 2: The table indicates the reduction from the control of RAW264.7 macrophages inflammatory response in the presence of 0 , $0.1,10$, and $100 \mathrm{ng} / \mathrm{mL}$ Rapamycin (up) and Rapamycin and Torin $5 \mathrm{ng} / \mathrm{mL}$ (down).

\begin{tabular}{|c|c|c|c|c|c|}
\hline & $\begin{array}{c}\mathrm{TNF} \\
(\%-\mathrm{pg} / \mathrm{mL})\end{array}$ & $\begin{array}{c}\text { IL-1 } \\
(\%-p g / m L)\end{array}$ & $\begin{array}{c}\text { IL-6 } \\
\text { (\%-pg/mL) }\end{array}$ & $\begin{array}{c}\text { INF } \\
(\%-p g / m L) \\
\end{array}$ & $\begin{array}{c}\mathrm{NO} \\
(\%-\mu \mathrm{M})\end{array}$ \\
\hline \multicolumn{6}{|c|}{ Rapamycin (ng/mL) } \\
\hline 0 & $\begin{array}{c}100 \% \\
32,758 \pm 3,603\end{array}$ & $\begin{array}{c}100 \% \\
486 \pm 58\end{array}$ & $\begin{array}{c}100 \% \\
799 \pm 96\end{array}$ & $\begin{array}{c}100 \% \\
87 \pm 10\end{array}$ & $\begin{array}{c}100 \% \\
22.1 \pm 2.7\end{array}$ \\
\hline 0.1 & $115 \%^{*}$ & $100 \%$ & $113 \%^{*}$ & $102 \%$ & $115 \%{ }^{*}$ \\
\hline 10 & $66 \%{ }^{*}$ & $62 \%^{*}$ & $75 \%{ }^{*}$ & $65 \%{ }^{*}$ & $64 \%^{*}$ \\
\hline 100 & $64 \%^{*}$ & $61 \%^{*}$ & $81 \%^{*}$ & $67 \%{ }^{*}$ & $63 \%{ }^{*}$ \\
\hline \multicolumn{6}{|c|}{$\begin{array}{l}\text { Rapamycin and Torin } \\
\text { at } 5 \mathrm{ng} / \mathrm{mL}\end{array}$} \\
\hline 0 and no Torin & $\begin{array}{c}100 \% \\
34,231 \pm 3,765\end{array}$ & $\begin{array}{c}100 \% \\
396 \pm 48\end{array}$ & $\begin{array}{c}100 \% \\
831 \pm 100\end{array}$ & $\begin{array}{c}100 \% \\
89 \pm 11\end{array}$ & $\begin{array}{c}100 \% \\
22.7 \pm 2.7\end{array}$ \\
\hline 0.1 & $49 \%^{*}$ & $43 \%^{*}$ & $80 \% *$ & $50 \%^{*}$ & $54 \%^{*}$ \\
\hline 10 & $43 \% *$ & $40 \% *$ & $79 \% *$ & $47 \% *$ & $48 \%{ }^{*}$ \\
\hline 100 & $41 \%^{*}$ & $39 \%{ }^{*}$ & $83 \%{ }^{*}$ & $44 \%^{*}$ & $43 \%^{*}$ \\
\hline
\end{tabular}

The first line indicates the response without Rapamycin (up) or without Rapamycin and Torin (down) which is used as control (100\% response) and the subsequent values are expressed as $\%$ of such responses.

${ }^{*}$ Indicates statistical significance $(P<0.05)$ from the control.

TNF: tumor necrosis factor, IL-1: interleukin 1, IL-6: interleukin 6, INF: interferon, and NO: nitric oxide.

$0.1 \mathrm{ng} / \mathrm{mL}$ (486 pg/mL: 100\%). However, at 10 and $100 \mathrm{ng} / \mathrm{mL}$ Rapamycin, the IL-1 response decreased to $301 \mathrm{ng} / \mathrm{mL}(62 \%)$ and $297 \mathrm{ng} / \mathrm{mL}$ (61\%); both differed significantly from the control. When Torin $5 \mathrm{ng} / \mathrm{mL}$ was added to the same experiment (Rapamycin at doses 0, 0.1, 10, and $10 \mathrm{ng} / \mathrm{mL}$ ), a reduction of $49 \%, 43 \%$, and $41 \%$, respectively, was noticed. All were significant different than the control response of $34,231 \mathrm{pg} / \mathrm{mL}(P<0.05)$ but not significantly different than each other. Therefore, the increase of cytokine response observed at $0.1 \mathrm{ng} / \mathrm{mL}$ of Rapamycin alone was eliminated (100\% response without Torin and $49 \%$ with Torin). Similar results were noticed with the other cytokines. The results of the other cytokines are presented in Table 2 and Figure 2. The viability of the cells during the experiment was tested as described in Section 2.

3.3. Rapamycin and KU63794 $5 \mathrm{ng} / \mathrm{mL}$. Similar to the Rapamycin-Torin experiment, the effects of $0,0.1,10$, and $100 \mathrm{ng} / \mathrm{mL}$ of Rapamycin were compared to the same Rapamycin dosing and KU63794 $5 \mathrm{ng} / \mathrm{mL}$. The control without Rapamycin was $32,865 \mathrm{pg} / \mathrm{mL}$ and addition of $0.1 \mathrm{ng} / \mathrm{mL}$ Rapamycin increased the TNF average to $42,171 \mathrm{pg} / \mathrm{mL}$, that is, $120 \%$, as was observed in the previous experiment. The 10 and $100 \mathrm{ng} / \mathrm{mL}$ of Rapamycin addition decreased TNF to $65 \%$ and $64 \%$ to the control level, all of which were significantly different $(P<0.05)$. KU63794 at $5 \mathrm{ng} / \mathrm{mL}$ blunted the $0.1 \mathrm{ng} / \mathrm{mL}$ Rapamycin-induced TNF response to $69 \%$ of the control. The 10 and $100 \mathrm{ng} / \mathrm{mL}$ of Rapamycin with $5 \mathrm{ng} / \mathrm{mL}$ KU63794 were 53\% and 49\%, all significantly different than the control (0.05), but not from each other. The IL-1 response had a similar pattern with an increase at $0.1 \mathrm{ng} / \mathrm{mL}$ of Rapamycin (113\% of the control) but a decrease to $43 \%$ of the control, when $\mathrm{KU} 637945 \mathrm{ng} / \mathrm{mL}$ was added. The results are presented in Table 3 and depicted as graphs in
Figure 3. The viability of the cells was tested as described in Section 2.

3.4. Activation of mTOR. The phosphorylated/total mTOR cell fraction for the control (stimulated by MRSA cells without inhibitor) was 1.82. At the presence of Rapamycin 0.1, 1,10 , and $100 \mathrm{ng} / \mathrm{mL}$, the results were $1.56,0.82,0.46$, and 0.43 ; thus, increasing dose of Rapamycin exhibited incremental suppression.

When Torin or KU63794 at dose 1 or dose $5 \mathrm{ng} / \mathrm{mL}$ was added, the fraction was $0.75,0.32,0.81$, and 0.35 respectively. Therefore, the phosphorylated/total mTOR fraction at the presence of inhibitors, Rapamycin, Torin, or KU63794, was dose-dependent in all inhibitors. The activation fraction was the same for Rapamycin 10 or $100 \mathrm{ng} / \mathrm{mL}$, Torin $5 \mathrm{ng} / \mathrm{mL}$, or KU63794 5 ng/mL used $(P<0.05)$ - see Figure 4.

\section{Discussion}

The roles of Rapamycin, an incomplete dose-dependent mTORC inhibitor, and the more potent mTOR inhibitors Torin/KU63794 are explored in the context of severe inflammation.

Consistent with our previous studies, we found that lowdose Rapamycin does not suppress but instead stimulates TNF production [7]. At higher doses, Rapamycin suppresses production of these cytokines. However, when combined with Torin or KU63794, we find that the induction effect is no longer present. Higher dose of Rapamycin alone or with Torin or KU63794 suppresses cytokine production. The data shows this suppression to be consistent with the production of TNF, INF, IL-1, IL-6, and NO. Although the Rapamycin $0.1 \mathrm{ng} / \mathrm{mL}$ induction was relatively small $(10-20 \%)$, it has significantly different response if it is compared with 

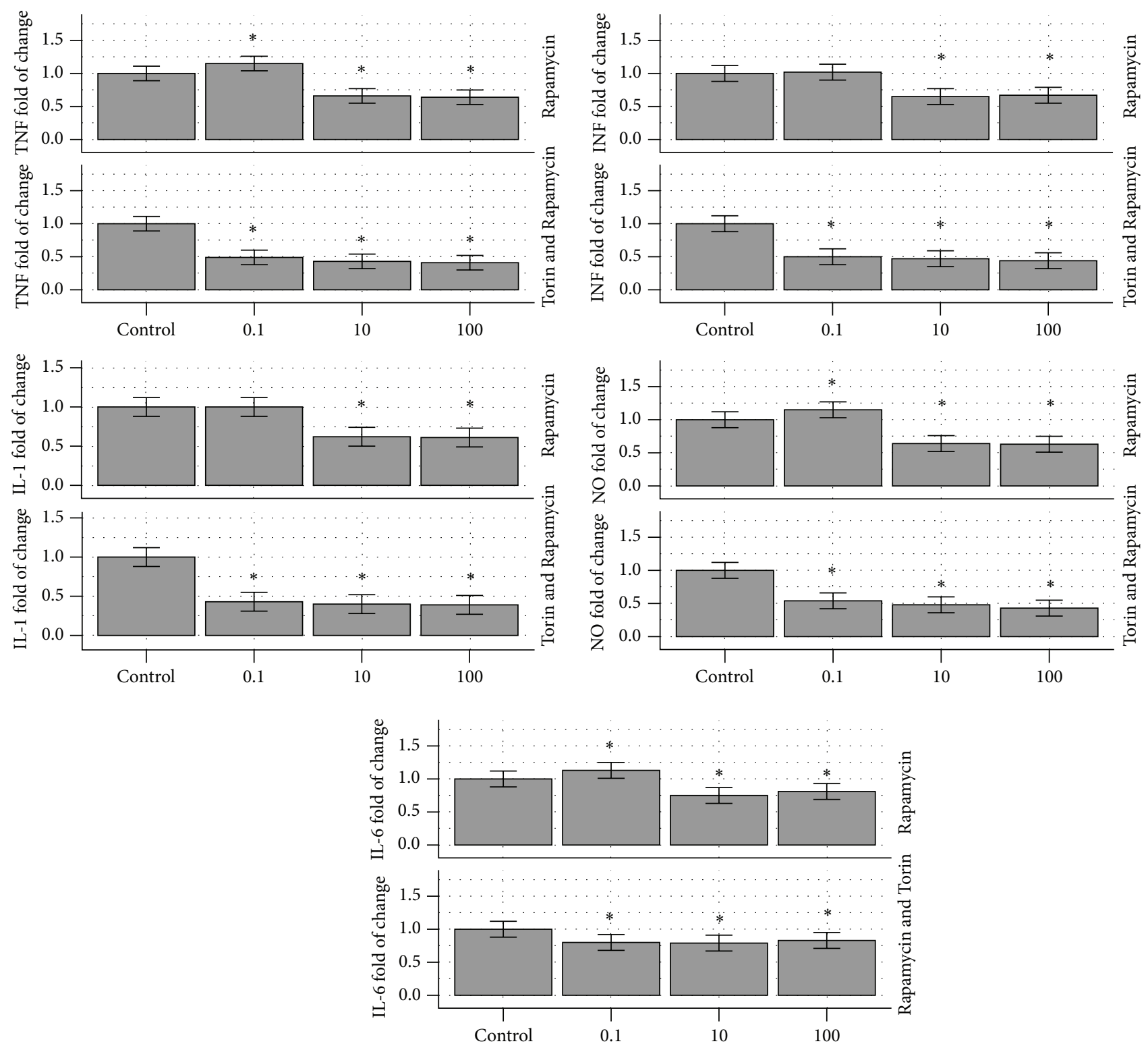

FIGURE 2: A graphic representation of Table 2. It indicates the reduction from the control of RAW264.7 macrophages inflammatory response of TNF, IL-1, IL-6, INF, and NO, respectively, in the presence of $0,0.1,10$, and $100 \mathrm{ng} / \mathrm{mL}$ Rapamycin (up) and Rapamycin and Torin $5 \mathrm{ng} / \mathrm{mL}$ (down). The graphs are depicted as a percent of the control response, that is, without Rapamycin (up) or Rapamycin and Torin (down). TNF: tumor necrosis factor, IL-1: interleukin 1, IL-6: interleukin 6, INF: interferon, and NO: nitric oxide.

the $60 \%$ suppression induced with higher doses. Such difference (60\%) may allow significant cytokine and clinical response manipulation at various stages of sepsis. It can possibly explain the variability in clinical course occasionally seen in septic patient taking Rapamycin. Torin and KU63794 suppress the TNF, INF, IL-1, IL-6, and NO up to $50 \%$ of the control in a dose related mode without exhibiting an induction.

The assessment of phospho(Ser2448)/total mTOR at various Rapamycin doses was not able to explain the biphasic TNF elevation, since it was dose-dependent as expected. Similarly, Torin and KU63794 exhibited also dose-dependent suppression.
Rapamycin has been described as dose-dependent inhibitor in cancer cell metabolism [26-28]. The more complete inhibition of Torin and KU63794 has been generally attributed to mTORC2 inhibition, although more complete inhibition of mTORC1 is possible $[19,29]$. Rapamycin's mTORC inhibition is also dependent on phospholipase D activity. Elevated phospholipase D seems to increase the Rapamycin resistance to mTOR inhibition [26, 27, 30, 31].

We surmise that the suppression of cytokine production is a result of the relative amount of inhibition of $\mathrm{MTORC1}$ and mTORC2, since phospholipase D activity had to be similar between the experiments. Thus, the proportional inhibition of mTORC2 or more complete inhibition of $\mathrm{mTORC1}$ appears 

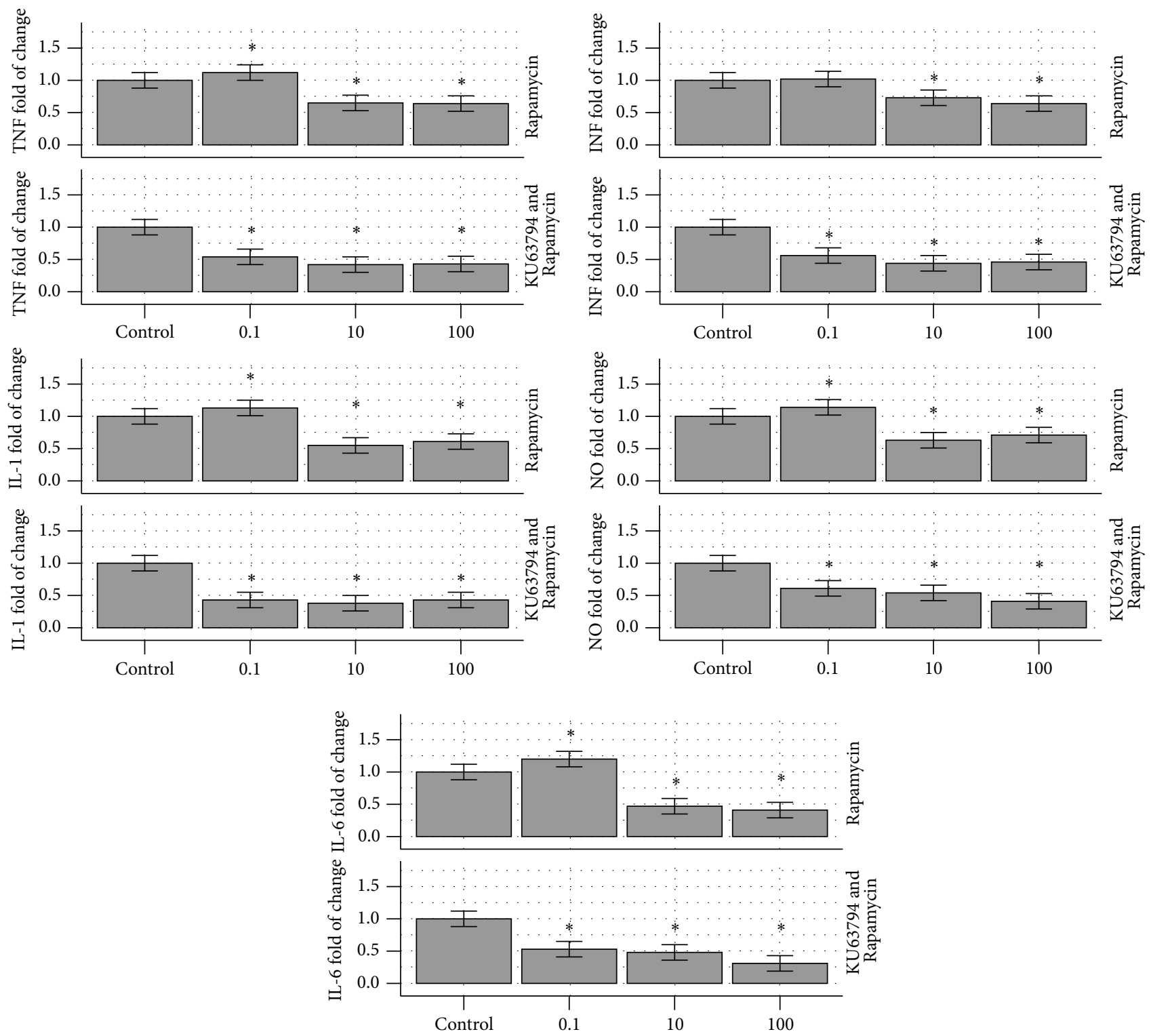

FIGURE 3: A graphic representation of Table 3. It indicates the reduction from the control of RAW264.7 macrophages inflammatory response of TNF, IL-1, IL-6, INF, and NO, respectively, in the presence of 0, 0.1, 10, and $100 \mathrm{ng} / \mathrm{mL}$ Rapamycin (up) and Rapamycin and KU63794 $5 \mathrm{ng} / \mathrm{mL}$ (down). The graphs are depicted as a percent of the control response, that is, without Rapamycin (up) or Rapamycin and KU63794 (down). TNF: tumor necrosis factor, IL-1: interleukin 1, IL-6: interleukin 6, INF: interferon, and NO: nitric oxide.

to have a suppressive effect on cytokine production in a murine macrophage model.

There is an inherent limitation of applicability when comparing in vitro murine macrophages to an in vivo model. The influence of Rapamycin to the Staphylococcal Toxic Shock has been studied $[32,33]$. However, our findings add the existence of a Rapamycin dose diphasic effect in the cytokine production. Such effect does not exist in other mTOR inhibitors like Torin and KU63794.

\section{Conclusion}

Rapamycin offers a significant biphasic induction and suppression of the inflammatory cascade. Torin and KU63794 offer a dose related suppression of inflammatory cytokines. Addition of Torin and KU63794 appears to blunt the Rapamycin induction and converting it to a dose related suppression. The present study performed in a cell culture sepsis simulation model describes the difference but more studies are needed to define the exact contribution of mTOR1 and mTOR2. However, understanding and further exploring the differential response of mTOR inhibitors in inflammation can lead to a clinically advantageous cytokine modulation based on Rapamycin dosing or Torin and KU63794 combination. The battle of sepsis especially in immunosuppressed patients requires understanding of the balance of immune overactivity and immunosuppression. Small but decisive regulations at appropriate phases may offer significant clinical advantages. 
TABLE 3: The table indicates the reduction from the control of RAW264.7 macrophages inflammatory response in the presence of 0, 0.1, 10, and 100 ng/mL Rapamycin (up) and Rapamycin and KU63794 5 ng/mL (down).

\begin{tabular}{|c|c|c|c|c|c|}
\hline & $\begin{array}{c}\text { TNF } \\
(\%-p g / m L)\end{array}$ & $\begin{array}{c}\text { IL-1 } \\
(\%-p g / m L)\end{array}$ & $\begin{array}{c}\text { IL-6 } \\
(\%-p g / m L)\end{array}$ & $\begin{array}{c}\text { INF } \\
(\%-p g / m L)\end{array}$ & $\begin{array}{c}\mathrm{NO} \\
(\%-\mu \mathrm{M})\end{array}$ \\
\hline \multicolumn{6}{|c|}{ Rapamycin (ng/mL) } \\
\hline \multirow{2}{*}{0} & $100 \%$ & $100 \%$ & $100 \%$ & $100 \%$ & $100 \%$ \\
\hline & $35,143 \pm 4,217$ & $496 \pm 60$ & $834 \pm 100$ & $91 \pm 11$ & $24.3 \pm 2.9$ \\
\hline 0.1 & $120 \% *$ & $113 \%^{*}$ & $120 \% *$ & $102 \%$ & $110 \%{ }^{*}$ \\
\hline 10 & $65 \%{ }^{*}$ & $55 \%{ }^{*}$ & $47 \%^{*}$ & $73 \% *$ & $63 \%^{*}$ \\
\hline 100 & $64 \%{ }^{*}$ & $61 \%^{*}$ & $41 \%^{*}$ & $64 \%^{*}$ & $71 \%^{*}$ \\
\hline \multicolumn{6}{|c|}{$\begin{array}{l}\text { Rapamycin and KU63794 } \\
\text { at } 5 \mathrm{ng} / \mathrm{mL}\end{array}$} \\
\hline \multirow{2}{*}{0} & $100 \%$ & $100 \%$ & $100 \%$ & $100 \%$ & $100 \%$ \\
\hline & $32,865 \pm 3,944$ & $432 \pm 42$ & $743 \pm 89$ & $95 \pm 11$ & $23.2 \pm 2.8$ \\
\hline 0.1 & $69 \% *$ & $43 \%{ }^{*}$ & $53 \%^{*}$ & $56 \% *$ & $61 \%^{*}$ \\
\hline 10 & $53 \%{ }^{*}$ & $38 \% *$ & $48 \%^{*}$ & $44 \% *$ & $54 \%^{*}$ \\
\hline 100 & $49 \%^{*}$ & $43 \%^{*}$ & $31 \%^{*}$ & $46 \%^{*}$ & $41 \%^{*}$ \\
\hline
\end{tabular}

The first line indicates the response without Rapamycin (up) or without Rapamycin and KU63794 (down) which is used as control (100\% response) and the subsequent values are expressed as $\%$ of such responses.

${ }^{*}$ Indicates statistical significance $(P<0.05)$ from the control.

TNF: tumor necrosis factor, IL-1: interleukin 1, IL-6: interleukin 6, INF: interferon, and NO: nitric oxide.

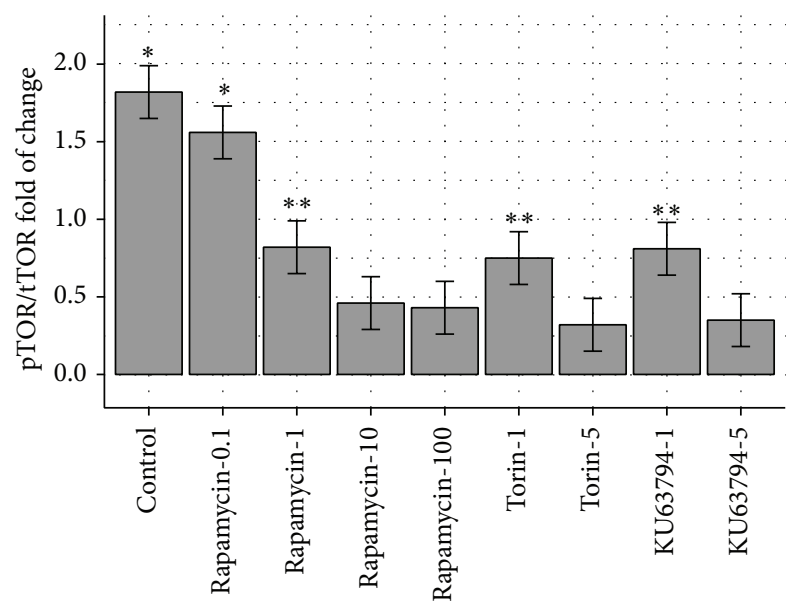

FIGURE 4: A graphic representation of activated mTOR expressed as phosphor/total mTOR. It indicates the activated fraction at the control (without inhibitor) with Rapamycin at doses 0.1, 10, and $100 \mathrm{ng} / \mathrm{mL}$, Torin at doses 1 and $5 \mathrm{ng} / \mathrm{mL}$, and KU63794 at doses 1 and $5 \mathrm{ng} / \mathrm{mL}$. Rap-0.1: Rapamycin $0.1 \mathrm{ng} / \mathrm{mL}$, Rap1: Rapamycin 1ng/mL, Rap-10: Rapamycin 10 ng/mL, Rap-100: Rapamycin 100 ng/mL, Tor-1: Torin $1 \mathrm{ng} / \mathrm{mL}$, Tor-5: Torin $5 \mathrm{ng} / \mathrm{mL}$, KU-1: KU63794 $1 \mathrm{ng} / \mathrm{mL}$, and KU-5: KU63794 5 ng/mL.

\section{Highlights}

(i) Rapamycin exhibits a dose related biphasic influence to the inflammatory cascade. (ii) Torin and KU63794 (mTOR 1 and 2 inhibitors) suppress the inflammatory response. (iii) Addition of Torin or KU63794 converts Rapamycin's response to suppression.

\section{Conflict of Interests}

The authors have no conflicts of interest relevant to this paper to disclose.

\section{Authors' Contribution}

Rebekah K. H. Shappley and Thomas Spentzas contributed to the acquisition of data. Rebekah K. H. Shappley and Thomas Spentzas contributed to the conception and design and interpretation of the data. Thomas Spentzas contributed to the statistical analysis. Thomas Spentzas and Rebekah K. H. Shappley gave the final approval.

\section{Acknowledgments}

The study was supported by a Grant (no. 641001) from the Children's Foundation Research Institute at Le Bonheur Children's Hospital. Parts of this paper were presented at the 42nd Critical Care Congress, San Juan, Puerto Rico, January 19-23, 2013 (Abstract).

\section{References}

[1] I. Cinel and S. M. Opal, "Molecular biology of inflammation and sepsis: a primer," Critical Care Medicine, vol. 37, no. 1, pp. 291304, 2009.

[2] E. S. Van Amersfoort, T. J. C. Van Berkel, and J. Kuiper, "Receptors, mediators, and mechanisms involved in bacterial sepsis and septic shock," Clinical Microbiology Reviews, vol. 16, no. 3, pp. 379-414, 2003.

[3] C. Ronco, C. Tetta, F. Mariano et al., "Interpreting the mechanisms of continuous renal replacement therapy in sepsis: the peak concentration hypothesis," Artificial Organs, vol. 27, no. 9, pp. 792-801, 2003.

[4] C. Woiciechowsky, K. Asadullah, D. Nestler et al., "Diminished monocytic HLA-DR expression and ex vivo cytokine secretion capacity in patients with glioblastoma: effect of tumor extirpation," Journal of Neuroimmunology, vol. 84, no. 2, pp. 164-171, 1998.

[5] M. W. Hall, N. L. Knatz, C. Vetterly et al., "Immunoparalysis and nosocomial infection in children with multiple organ 
dysfunction syndrome," Intensive Care Medicine, vol. 37, no. 3, pp. 525-532, 2011.

[6] T. Spentzas, R. K. H. Shapley, C. A. Aguirre et al., "Ketamine inhibits tumor necrosis factor secretion by RAW264.7 murine macrophages stimulated with antibiotic-exposed strains of community-associated, methicillin-resistant Staphylococcus aureus," BMC Immunology, vol. 12, article 11, 2011.

[7] T. Spentzas, R. K. Shappley, F. Savorgnan, E. Meals, and B. K. English, "Rapamycin augments the NMDA-mediated TNF suppression of MRSA-stimulated RAW264. 7 murine macrophages," International Journal of Inflammation, vol. 2012, Article ID 542727, 10 pages, 2012.

[8] S. Huang and P. J. Houghton, "Targeting mTOR signaling for cancer therapy," Current Opinion in Pharmacology, vol. 3, no. 4, pp. 371-377, 2003.

[9] A. F. Shamji, P. Nghiem, and S. L. Schreiber, "Integration of growth factor and nutrient signaling: implications for cancer biology," Molecular Cell, vol. 12, no. 2, pp. 271-280, 2003.

[10] F. McKeon, "When worlds collide: immunosuppresants meet protein phosphatases," Cell, vol. 66, no. 5, pp. 823-826, 1991.

[11] E. J. Brown, M. W. Albers, T. B. Shin et al., "A mammalian protein targeted by G1-arresting rapamycin-receptor complex," Nature, vol. 369, no. 6483, pp. 756-758, 1994.

[12] J. Chung, C. J. Kuo, G. R. Crabtree, and J. Blenis, "RapamycinFKBP specifically blocks growth-dependent activation of and signaling by the $70 \mathrm{kd}$ S6 protein kinases," Cell, vol. 69, no. 7, pp. 1227-1236, 1992.

[13] S. Huang, M.-A. Bjornsti, and P. J. Houghton, "Rapamycins: mechanism of action and cellular resistance," Cancer Biology and Therapy, vol. 2, no. 3, pp. 222-232, 2003.

[14] C. J. Sabers, M. M. Martin, G. J. Brunn et al., "Isolation of a protein target of the FKBP12-rapamycin complex in mammalian cells," Journal of Biological Chemistry, vol. 270, no. 2, pp. 815$822,1995$.

[15] N. Hay and N. Sonenberg, "Upstream and downstream of mTOR," Genes and Development, vol. 18, no. 16, pp. 1926-1945, 2004.

[16] L. Finelli, A. Fiore, R. Dhara et al., "Influenza-associated pediatric mortality in the united states: increase of Staphylococcus aureus coinfection," Pediatrics, vol. 122, no. 4, pp. 805-811, 2008.

[17] E. A. Abdi, J. C. Ding, and I. A. Cooper, "Nocardia infection in splenectomized patients: case reports and a review of the literature," Postgraduate Medical Journal, vol. 63, no. 740, pp. 455-458, 1987.

[18] A. M. Woltman, J. W. De Fijter, S. W. A. Kamerling et al., "Rapamycin induces apoptosis in monocyte- and CD34derived dendritic cells but not in monocytes and macrophages," Blood, vol. 98, no. 1, pp. 174-180, 2001.

[19] H. Zhou, Y. Luo, and S. Huang, "Updates of mTOR inhibitors," Anti-Cancer Agents in Medicinal Chemistry, vol. 10, no. 7, pp. 571-581, 2010.

[20] C. C. Thoreen, S. A. Kang, J. W. Chang et al., "An ATPcompetitive mammalian target of rapamycin inhibitor reveals rapamycin-resistant functions of mTORC1," Journal of Biological Chemistry, vol. 284, no. 12, pp. 8023-8032, 2009.

[21] "Four pediatric deaths from community-acquired MethicillinResistant Staphylococcus aureus-Minnesota and North Dakota, 1997-1999," Morbidity and Mortality Weekly Report, vol. 48, no. 32, pp. 707-710, 1999.

[22] T. Spentzas, R. Kudumula, C. Acuna et al., "Role of bacterial components in macrophage activation by the LAC and MW2 strains of community-associated, methicillin-resistant Staphylococcus aureus," Cellular Immunology, vol. 269, no. 1, pp. 4653, 2011.

[23] A. Barilli, R. Visigalli, R. Sala et al., "In human endothelial cells rapamycin causes $\mathrm{mTORC} 2$ inhibition and impairs cell viability and function," Cardiovascular Research, vol. 78, no. 3, pp. 563571, 2008.

[24] B. K. English, E. M. Maryniw, A. J. Talati, and E. A. Meals, "Diminished macrophage inflammatory response to Staphylococcus aureus isolates exposed to daptomycin versus vancomycin or oxacillin," Antimicrobial Agents and Chemotherapy, vol. 50, no. 6, pp. 2225-2227, 2006.

[25] T. L. Riss and R. A. Moravec, "Use of multiple assay endpoints to investigate the effects of incubation time, dose of toxin, and plating density in cell-based cytotoxicity assays," Assay and Drug Development Technologies, vol. 2, no. 1, pp. 51-62, 2004.

[26] Y. Chen, Y. Zheng, and D. A. Foster, "Phospholipase D confers rapamycin resistance in human breast cancer cells," Oncogene, vol. 22, no. 25, pp. 3937-3942, 2003.

[27] Y. Chen, V. Rodrik, and D. A. Foster, "Alternative phospholipase $\mathrm{D} / \mathrm{mTOR}$ survival signal in human breast cancer cells," Oncogene, vol. 24, no. 4, pp. 672-679, 2005.

[28] K. Yu, L. Toral-Barza, C. Discafani et al., "mTOR, a novel target in breast cancer: the effect of CCI-779, an mTOR inhibitor, in preclinical models of breast cancer," Endocrine-Related Cancer, vol. 8, no. 3, pp. 249-258, 2001.

[29] D. A. Foster and A. Toschi, "Targeting mTOR with rapamycin: one dose does not fit all," Cell Cycle, vol. 8, no. 7, pp. 1026-1029, 2009.

[30] Y. Sun and J. Chen, "mTOR signaling: PLD takes center stage," Cell Cycle, vol. 7, no. 20, pp. 3118-3123, 2008.

[31] Y. Sun, Y. Fang, M.-S. Yoon et al., "Phospholipase D1 is an effector of Rheb in the mTOR pathway," Proceedings of the National Academy of Sciences of the United States of America, vol. 105, no. 24, pp. 8286-8291, 2008.

[32] T. Krakauer and M. Buckley, "Intranasal rapamycin rescues mice from staphylococcal enterotoxin B-induced shock," Toxins, vol. 4, no. 9, pp. 718-728, 2012.

[33] T. Krakauer, "PI3K/Akt/mTOR, a pathway less recognized for staphylococcal superantigen-induced toxicity," Toxins, vol. 4, no. 11, pp. 1343-1366, 2012. 


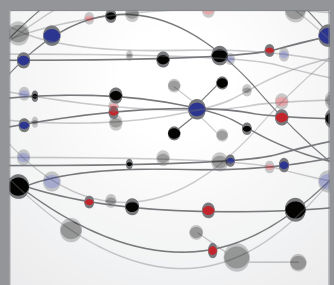

The Scientific World Journal
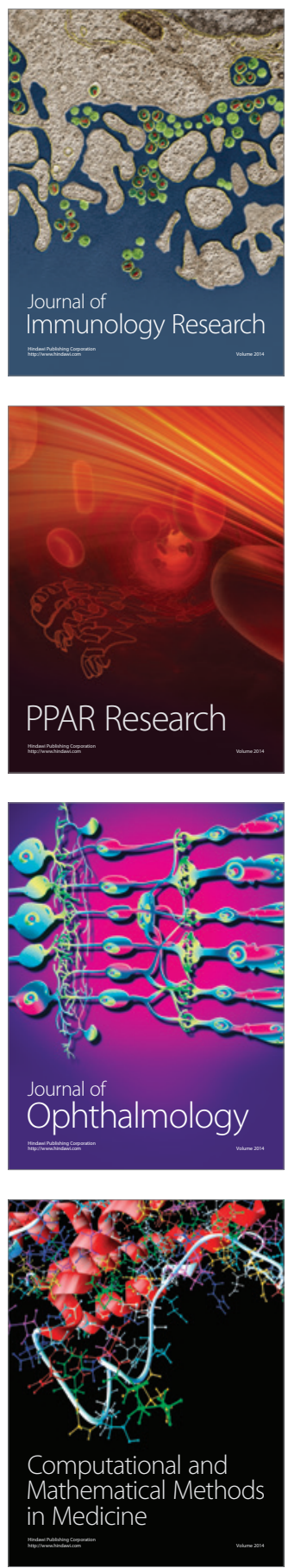

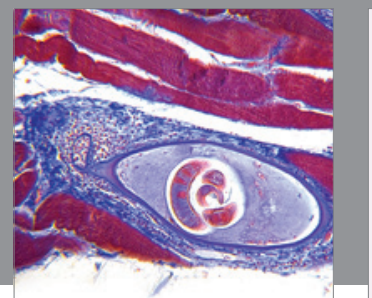

Gastroenterology

Research and Practice
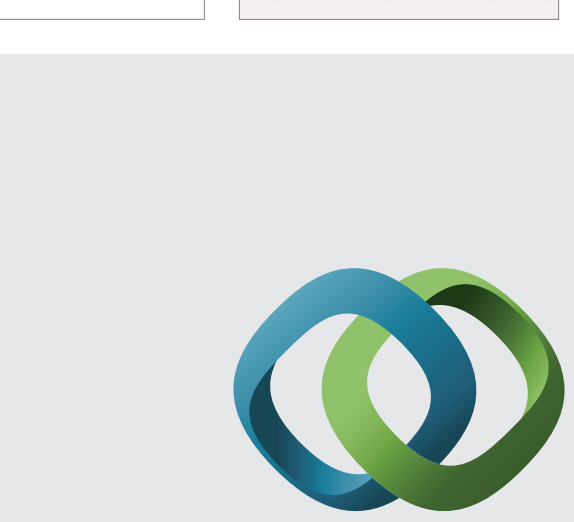

\section{Hindawi}

Submit your manuscripts at

http://www.hindawi.com
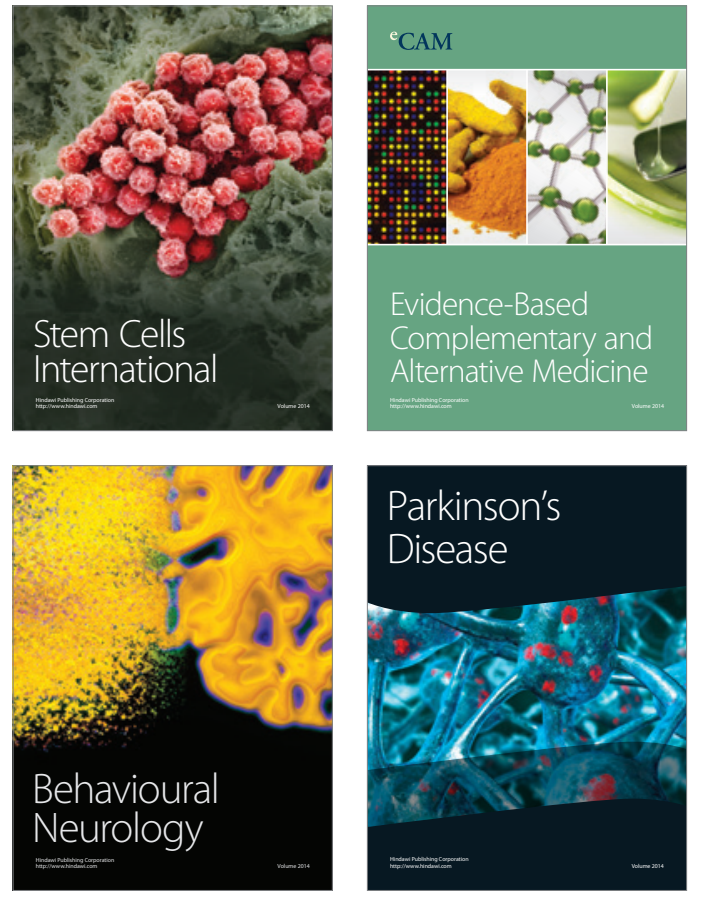
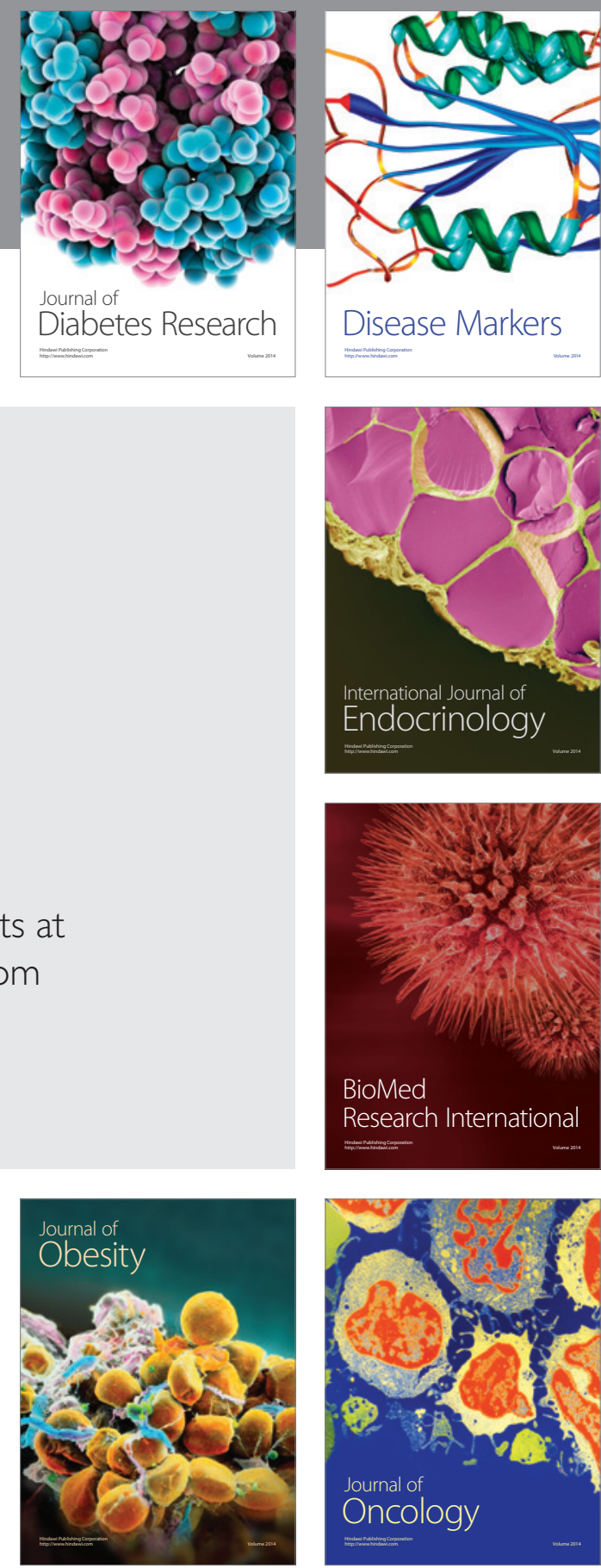

Disease Markers
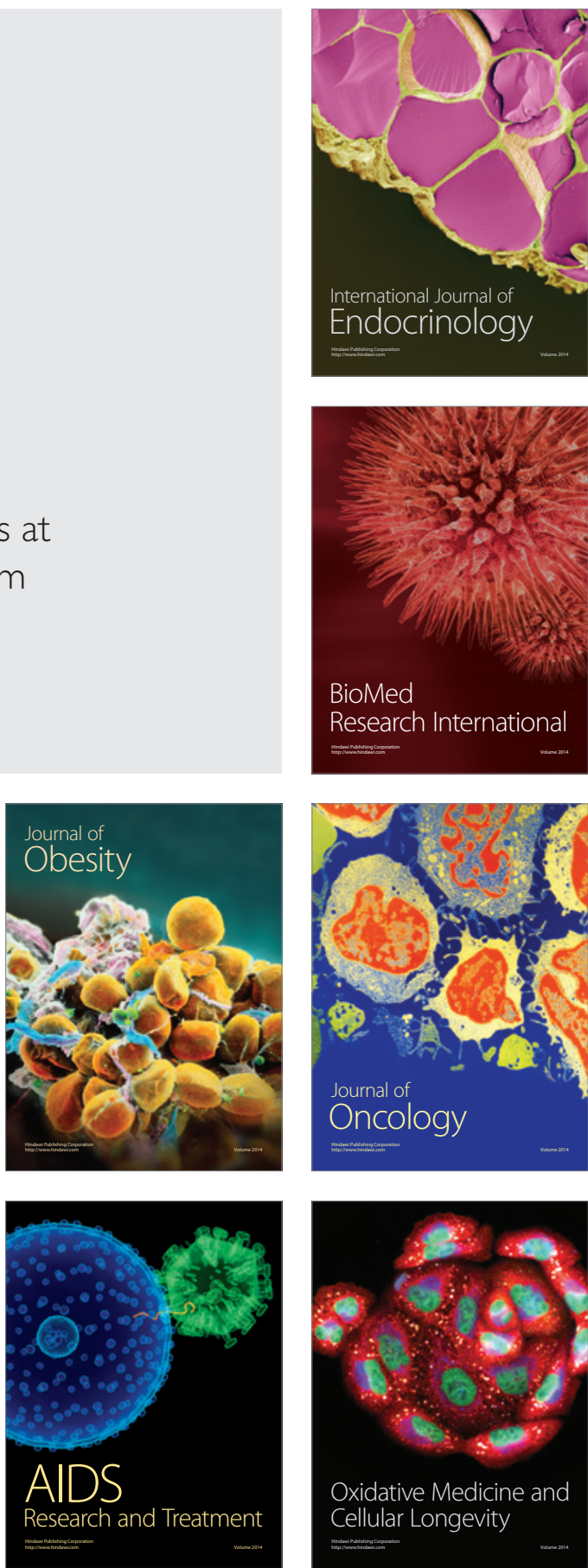